\title{
Residues and Dissipation of Deltamethrin 10 EC in/on Onion and Cropped Soil
}

\author{
C.S. Patil*, S.A. Landge, Y.S. Saindane and B.V. Deore \\ All India Network Project on Pesticide Residues, Department of Entomology, Mahatma Phule \\ Krishi Vidyapeeth, Rahuri, Ahmednagar, Maharashtra, India \\ *Corresponding author
}

\section{A B S T R A C T}

The field experiment was conducted during the Kharif, 2014 at University Farm, Post

Keywords

Onion,

Deltamethrin,

Persistence and QuEChERS

Article Info

Accepted:

02 May 2018

Available Online:

10 June 2018
Graduate Institute, MPKV, Rahuri, District Ahmednagar to determine the residues and dissipation of deltamethrin $10 \mathrm{EC}$ in/on onion and in soil. Three sprays of deltamethrin 10 EC were given at an interval of 10 days initiating first spray at bulb formation stage @ 15 $\mathrm{g}$ a.i./ha. (150 ml/ha) and $30 \mathrm{~g}$ a.i./ha $(300 \mathrm{ml} / \mathrm{ha})$. Samples were collected periodically at $0,3,5,7,10$ and $15^{\text {th }}$ day after last spray. The mature onion and soil samples were collected at harvest. The samples were analysed for insecticide residues by using validated QuEChERS method on Gas Chromatography Mass spectrometry. The results revealed that average initial residues of deltamethrin in immature onion were found to be 1.30 and 2.33 $\mathrm{mg} / \mathrm{kg}$ at single and double dose, respectively and reached BDL on $10^{\text {th }}$ and $15^{\text {th }}$ days, respectively for both the doses, whereas no residues were detected in the untreated control samples. The half-life values of deltamethrin were observed to be 1.57 and 1.77 days, for single and double doses, respectively. The residues of deltamethrin in mature onion and in soil at harvest were found to be BQL. Soil sample collected after harvest did not reveal the presence of deltamethrin residues.

\section{Introduction}

Onion (Allium cepa L.) belongs to the family Alliaceae; it is one of the most important commercial vegetable grown widely by large, small and marginal farmers in different parts of the country. It is mostly used as salad, pickles and garnish in cooked, fried, boiled and baked curries. Dietary demand of onion is increasing day by day due to the awareness of nutritional and medicinal importance. Globally onions are grown in an area of 4.45 mha with a production of $85.94 \mathrm{mt}$ of an average productivity of $19.30 \mathrm{t} / \mathrm{ha}$. India is one of the leading onions growing country with an area of 1.2 mha with a production of $19.40 \mathrm{mt}$ after china followed by USA, Iran, Russian Federation, Egypt, Turkey, Pakistan, Brazil and Netherlands. In India onion is mainly grown in Maharashtra, Madhya-Pradesh, Karnataka, Gujarat, Bihar, Andhra Pradesh and Rajasthan (Manjunathagowda et al., 2015).

Deltamethrin $10 \mathrm{EC}$, is an emulsifiable concentrate formulation containing $10 \% \mathrm{w} / \mathrm{w}$ 
deltamethrin is a synthetic pyrethroid pesticide that kills insects through dermal contact and digestion. The presence of residues in onion is a matter of serious concern especially when onions are consumed. Therefore, it becomes mandatory to assess the impact of use of deltamethrin $10 \mathrm{EC}$ from residues point of view for the safety of the consumers. However, no information is available on persistence of deltamethrin on onion. Therefore, the present study was carried out to investigate the dissipation studies of deltamethrin residues in onion with the aim to asses risk to the consumer.

\section{Materials and Methods}

\section{Field experiment}

Study was initiated on onion (var. N-2-4-1) at University Farm, Post Graduate Institute, MPKV, Rahuri, Ahmednagar (M.S.) India during, Kharif, 2014. The experiment was laid in randomized block design (RBD). The first application of deltamethrin 10 EC @ 150 $\mathrm{ml} / \mathrm{ha}$ and $300 \mathrm{ml} / \mathrm{ha}$ were made at bulb formation stage using knapsack sprayer. Subsequently two applications were made at 10 day intervals. Each treatment was replicated thrice. Control plots were sprayed with water only. One $\mathrm{kg}$ immature onion samples were collected at random from each treatment at 0 (2 hr after spray), 3, 5, 7, 10 and 15 days after last application and soil samples were collected at harvest. Samples were brought to the pesticide residues laboratory and extracted immediately. The residues of deltamethrin were estimated on Gas Chromatography Mass Spectrometry.

\section{Chemicals and reagents}

The Certified Reference Material of high purity of deltamethrin (99.60\%) and commercial formulations were supplied by M/s Bayer Crop Science India Ltd., Mumbai.
All the solvents used were of analytical grade. The solvents of Ethyl Acetate (HPLC grade), Acetonitrile (HPLC grade), Sodium Chloride (AR grade), Magnesium Sulphate (AR grade), Sodium Sulphate anhydrous (AR grade) were obtained M/s. Rankem Fine Chemicals, Ltd., New Delhi. (India). PSA was procured from Agilent Technology, Bangalore.

The primary stock solutions of deltamethrin were prepared at $1000 \mathrm{mg} / \mathrm{kg}$ in Toluene. These solutions were further diluted to obtain working concentrations of $0.05,0.1,0.25,0.4$, $1.0 \mathrm{mg} / \mathrm{kg}$.

\section{Method validation}

Prior to analysis of samples, linearity of deltamethrin was established on GCMS. Accuracy and precision of the method was determined by per cent mean recovery and per cent relative standard deviation (RSD). Linearity was studied by injecting standard solution of insecticides under study at five linear concentrations i.e. $0.05,0.10,0.25,0.40$ and $0.50 \mathrm{mg} / \mathrm{kg}$.

The linearity curve was established with concentration of the standard and corresponding peak area. Recovery study was conducted in order to establish the reliability of the method of analysis. The onion samples from control plots were used for recovery studies. Ten g homogenized sample was taken in $15 \mathrm{ml}$ polypropylene tube. The samples were spiked with three different concentrations viz. $0.05 \mathrm{mg} / \mathrm{kg}$ (LOQ), 0.25 $\mathrm{mg} / \mathrm{kg}(5 \times \mathrm{LOQ})$ and $0.5 \mathrm{mg} / \mathrm{kg}(10 \times \mathrm{LOQ})$ in triplicate. The extraction and clean-up of sample was performed as described hereunder. Per cent recovery was calculated by using following formula.

Quantity of pesticide recovered Per cent recovery = ------------------- $\times 100$

Quantity of pesticide added 


\section{Sampling}

The onion bulb samples $(1 \mathrm{~kg})$ were collected at random from each replicate of the treated and control plots separately at regular time interval of 0 (2 hrs after spraying), 1, 3, 5, 7, 10 and 15 days after the second spray. The collected samples were brought to the laboratory in polythene bags and processed immediately.

\section{Extraction and clean up}

Treated onion bulbs were extracted by QuEChERS method (Sharma, 2013). The entire laboratory sample $(1 \mathrm{Kg})$ was crushed thoroughly in a mixer cum grinder. Weighed $10 \mathrm{~g}$ homogenized sample in a $50 \mathrm{ml}$ polypropylene tube and the tube was kept in deep freezer for $10 \mathrm{~min}$. To this, $10 \mathrm{ml}$ ethyl acetate and $10 \mathrm{~g}$ anhydrous sodium sulphate were added, hand shaken vigorously and centrifuged the content at $3500 \mathrm{rpm}$ for $5 \mathrm{~min}$.

$2 \mathrm{ml}$ supernatant was transferred to $15 \mathrm{ml}$ tube containing $50 \mathrm{mg}$ PSA. The content was vortexed for $30 \mathrm{Sec}$ and then centrifuged for 2 $\mathrm{min}$ at $2500 \mathrm{rpm}$. The supernatant was filtered through 0.2 micron filter in GC vials and performed GC-MS analysis. The operating parameters were as below

Column: VF 5 MS $30 \mathrm{~m}$ x $0.25 \mu$ x $0.25 \mu$

Column Temperature: $190{ }^{\circ} \mathrm{C}$ to $225{ }^{\circ} \mathrm{C} @ 3.5$ ${ }^{\circ} \mathrm{C}$ /min, 1min hold, $225{ }^{0} \mathrm{C}$ to $260{ }^{0} \mathrm{C} @ 3^{0}$ C/min, 3 min hold, $260^{\circ} \mathrm{C}$ to $280^{\circ} \mathrm{C} @ 7^{0}$ C/min, 5 min hold

Injector Temperature: $250^{\circ} \mathrm{C}$

Interface Temperature: $285^{\circ} \mathrm{C}$

Ion source Temperature: $220^{\circ} \mathrm{C}$

Injection volume $: 1 \mu 1$
Column flow : $1.37 \mathrm{ml} / \mathrm{min}$

Retention time Approx.: Deltamethrin: 29.12 $\min$

\section{Results and Discussion}

\section{Method validation}

The detector response to the neat standards of the insecticides was studied by injecting five linear concentrations of the deltamethrin insecticides. The graph was plotted with detector response against respective concentration and linearity line was drawn.

The response of the instrument was linear over the range tested and $\mathrm{R}^{2}$ value was 0.99 for insecticides (Fig. 1). These results indicated that the GCMS analysis is a valid method for residue determination of the tested insecticides in onion. Accuracy of the analytical method was determined by recovery studies. The per cent recovery was within acceptable range of 70-120 per cent prescribed by SANCO (SANCO, 2011) and mentioned in Table 1.

Residues were estimated by comparison of peak area of the standards with that of the unknown or spiked samples run under identical conditions.

\section{Dissipation of deltamethrin}

Residues of deltamethrin $\left(\mathrm{mg} \mathrm{kg}^{-1}\right)$ on onion at different time intervals after application @ 15 $\mathrm{g}$ a.i./ha $(150 \mathrm{ml} / \mathrm{ha})$ and $30 \mathrm{~g}$ a.i./ha (300 $\mathrm{ml} / \mathrm{ha}$ ) are presented in Table 2 . The average initial residues of deltamethrin on immature onion were observed to be 1.30 and 2.33 $\mathrm{mg} / \mathrm{kg}$ at single and double dose, respectively, following three applications of deltamethrin. Residues of deltamethrin dissipated below quantification limit of $0.05 \mathrm{mg} / \mathrm{kg}$ in 10 and 15 days at single and double dose, respectively. 
Table.1 Recovery of deltamethrin in/on onion

\begin{tabular}{|c|c|c|c|c|c|c|c|c|c|c|c|c|}
\hline \multirow[t]{3}{*}{ Substrate } & \multicolumn{12}{|c|}{ Per cent recovery at different fortification level } \\
\hline & \multicolumn{4}{|c|}{$0.05 \mathrm{mg} / \mathrm{kg}$} & \multicolumn{4}{|c|}{$0.25 \mathrm{mg} / \mathrm{kg}$} & \multicolumn{4}{|c|}{$0.5 \mathrm{mg} / \mathrm{kg}$} \\
\hline & R-I & R-II & R-III & Mean & R-I & R-II & R-III & Mean & R-I & R-II & R-III & Mean \\
\hline $\begin{array}{l}\text { Immature } \\
\text { onion }\end{array}$ & 83.82 & 82.41 & 84.71 & 83.65 & 94.33 & 96.46 & 97.40 & 96.06 & 94.74 & 90.47 & 93.97 & 93.06 \\
\hline $\begin{array}{l}\text { Mature } \\
\text { onion }\end{array}$ & 77.94 & 75.95 & 74.11 & 76.00 & 85.28 & 82.36 & 80.82 & 82.82 & 97.94 & 96.20 & 94.32 & 96.15 \\
\hline Soil & 73.40 & 71.75 & 76.41 & 73.85 & 90.81 & 88.63 & 92.27 & 90.57 & 91.84 & 78.72 & 76.91 & 79.15 \\
\hline
\end{tabular}

Table.2 Residues of deltamethrin $10 \mathrm{EC}$ in/on onion

\begin{tabular}{|c|c|c|c|c|c|c|c|c|c|c|c|c|}
\hline \multirow{3}{*}{\begin{tabular}{|l} 
Parameters \\
Immature \\
\end{tabular}} & \multicolumn{12}{|c|}{ Deltamethrin residues (mg/kg) } \\
\hline & \multicolumn{4}{|c|}{ Control } & \multicolumn{4}{|c|}{15 g.a.i./ha (150 ml /ha) } & \multicolumn{4}{|c|}{30 g.a.i./ha (300 ml/ha) } \\
\hline & $\mathbf{R}_{1}$ & $\mathbf{R}_{2}$ & $\mathbf{R}_{3}$ & Mean & $\mathbf{R}_{1}$ & $\mathbf{R}_{2}$ & $\mathbf{R}_{\mathbf{3}}$ & Mean & $\mathbf{R}_{1}$ & $\mathbf{R}_{2}$ & $\mathbf{R}_{3}$ & Mean \\
\hline $\mathbf{0}$ & ND & ND & ND & ND & 1.30 & 1.35 & 1.26 & 1.30 & 2.32 & 2.30 & 2.38 & 2.33 \\
\hline 3 & ND & ND & ND & ND & 0.81 & 0.82 & 0.85 & 0.83 & 1.55 & 1.41 & 1.33 & 1.43 \\
\hline 5 & ND & ND & ND & ND & 0.19 & 0.15 & 0.13 & 0.16 & 0.50 & 0.46 & 0.58 & 0.51 \\
\hline 7 & ND & ND & ND & ND & 0.06 & 0.07 & 0.08 & 0.07 & 0.24 & 0.22 & 0.28 & 0.25 \\
\hline 10 & ND & ND & ND & ND & BDL & BDL & BDL & BDL & 0.06 & 0.05 & 0.04 & 0.05 \\
\hline 15 & ND & ND & ND & ND & BDL & BDL & BDL & BDL & BDL & BDL & BDL & BDL \\
\hline $\begin{array}{c}\text { Mature } \\
\text { onion }\end{array}$ & ND & ND & ND & ND & BDL & BDL & BDL & BDL & BDL & BDL & BDL & BDL \\
\hline Soil & ND & ND & ND & ND & BDL & BDL & BDL & BDL & BDL & BDL & BDL & $\overline{\text { BDL }}$ \\
\hline $\mathbf{R L}_{\text {50(Days) }}$ & \multicolumn{4}{|c|}{--} & \multicolumn{4}{|c|}{1.57} & & & & 1.77 \\
\hline
\end{tabular}

ND-Not Detected BDL- below detection limit LOQ 0.05 mg/kg

Fig.1 Linearity deltamethrin

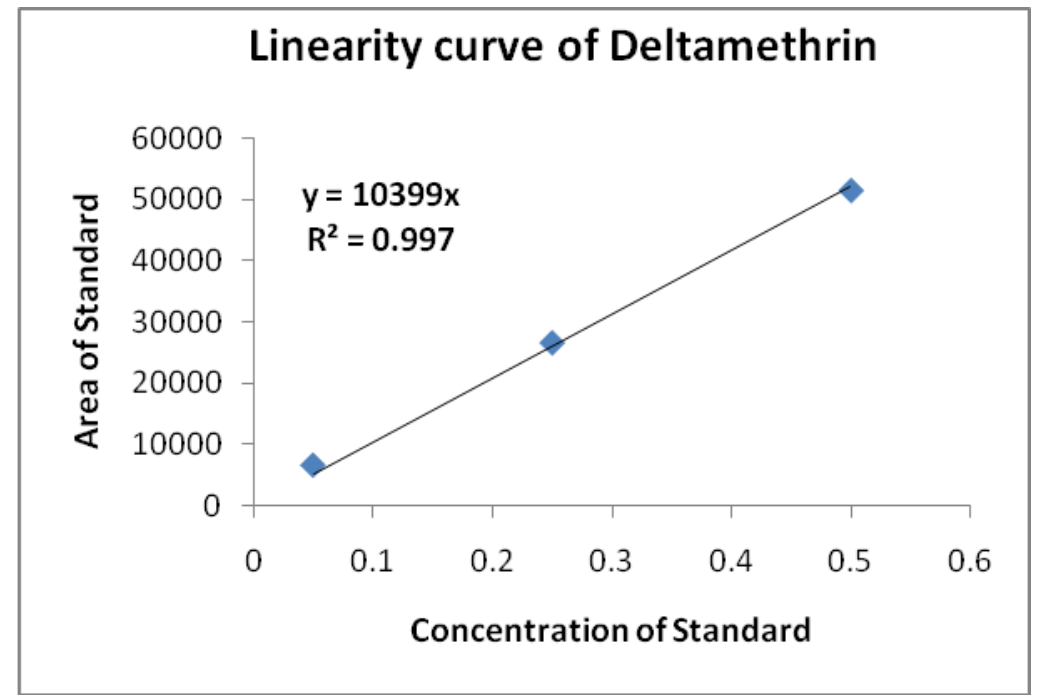


Half-life $\left(\mathrm{DT}_{50}\right)$ values of deltamethrin on immature onion were observed to be 1.57 and 1.77 days, respectively. Mature bulbs and soil samples collected at harvest did not reveal the presence of deltamethrin residues at quantification limit of $0.05 \mathrm{mg} / \mathrm{kg}$. These results are in agreement with findings of earlier workers (Sharma et al., 2018), who reported initial deposits of deltamethrin as $0.57,0.15,0.17,0.13 \mathrm{mg} / \mathrm{kg}$ on cucumber at the respective four centres (PJTSAU, BCKV, IIHR and PAU) at recommended and 1.05, $0.29,0.26,0.30 \mathrm{mg} / \mathrm{kg}$ at double the recommended dose, respectively. The residues of deltamethrin reached below quantitation limit after 10 and 15 days at recommended and double the recommended dose with a half-life of 2.5 to 4.9 days and 2.7 to 3.9 days at the locations mentioned above. On the basis of supervised field trial conducted with the deltamethrin 10 EC formulation on onion, two days pre harvest interval may be considered for adapting following application of $150 \mathrm{~g}$ a.i./ha

\section{Acknowledgements}

Authors are thankful to the Network Coordinator, AINP on Pesticide Residues, ICAR, New Delhi for providing necessary facilities for conducting studies and $\mathrm{M} / \mathrm{s}$. Bayer Crop Science for sponsoring supervised filed trial.

\section{References}

A. Manjunathagowda, D. C., Bomble Ram Y. and Todkar D. V. 2015. Prosperity of Onions in India. Popular Kheti. 3(3). pp. 33-39

SANCO (2011). Method Validation and quality control procedures for pesticide residue analysis in food and feed. Document No. 12495/2011. 8:15.

Sharma, K. K. 2013. Pesticide Residue Analysis Manual, ICAR, Gov. of India, pp. 90-91.

Sharma, K. K., V. Shashi Bhushan, Cherukuri Sreenivasa Rao, K. Narsimha Reddy, Hemanta Banerjee, Swagata Mandal, Balwinder Singh, R. S. Battu, Gagan Jyot, S. K. Sahoo, Soudamini Mohapatra, S. Lekha, Gourishankar Manikrao, B. Radhika, Vandana Tripathy, Rajbir Yadav, Poonam Shukla, Amar Nath Patel, Gitansh Singh, Suneeta Devi, Priya Pandey, Rahul Gautam, Shobhita Kalra, Ruchi Gupta, Geeta Singh, Madhuban Gopal and Suresh Walia. 2018. Persistence, dissipation and consumer risk assessment of a combination formulation of flubendiamide and deltamethrin on cucumber. Food Additives \& Contaminants: Part A. VOL. 35, NO. 3, 498-511

\section{How to cite this article:}

Patil, C.S., S.A. Landge, Y.S. Saindane and Deore, B.V. 2018. Residues and Dissipation of Deltamethrin 10 EC in/on Onion and Cropped Soil. Int.J.Curr.Microbiol.App.Sci. 7(06): 177181. doi: https://doi.org/10.20546/ijcmas.2018.706.022 